\title{
Addition of hydrogen peroxide for the simultaneous control of bromate and odor during advanced drinking water treatment using ozone
}

\author{
Yongjing Wang ${ }^{1}$, Jianwei Yu ${ }^{1, *}$, Dong Zhang ${ }^{2}$, Min Yang ${ }^{1}$ \\ 1. State Key Laboratory of Environmental Aquatic Chemistry, Research Center for Eco-Environmental Sciences, Chinese Academy of Sciences, \\ Beijing 100085, China \\ 2. Shanghai National Engineering Research Center of Urban Water Resources Co., Ltd., Shanghai 200082, China
}

\section{A R T I C L E I N F O}

\section{Article history:}

Received 27 March 2013

revised 05 May 2013

accepted 07 May 2013

Keywords:
ozonation
$\mathrm{H}_{2} \mathrm{O}_{2}$
$\mathrm{BrO}_{3}^{-}$suppression
septic/swampy odor
flavor profile analysis
DOI: $10.1016 / \mathrm{S} 1001-0742(13) 60409-\mathrm{X}$

\begin{abstract}
A B S T R A C T
Complete removal of the characteristic septic/swampy odor from Huangpu River source water could only be achieved under an ozone dose as high as $4.0 \mathrm{mg} / \mathrm{L}$ in an ozone-biological activated carbon $\left(\mathrm{O}_{3}\right.$ $\mathrm{BAC}$ ) process, which would lead to the production of high concentrations of carcinogenic bromate due to the high bromide content. This study investigated the possibility of simultaneous control of bromate and the septic/swampy odor by adding $\mathrm{H}_{2} \mathrm{O}_{2}$ prior to the $\mathrm{O}_{3}$-BAC process for the treatment of Huangpu River water. $\mathrm{H}_{2} \mathrm{O}_{2}$ addition could reduce the bromate concentration effectively at an $\mathrm{H}_{2} \mathrm{O}_{2} / \mathrm{O}_{3}(\mathrm{~g} / \mathrm{g})$ ratio of 0.5 or higher. At the same time, the septic/swampy odor removal was enhanced by the addition of $\mathrm{H}_{2} \mathrm{O}_{2}$, although optimization of the $\mathrm{H}_{2} \mathrm{O}_{2} / \mathrm{O}_{3}$ ratio was required for each ozone dose. At an ozone dose of $2.0 \mathrm{mg} / \mathrm{L}$, the odor was removed completely at an $\mathrm{H}_{2} \mathrm{O}_{2} / \mathrm{O}_{3}$ ratio of 0.5. The results indicated that $\mathrm{H}_{2} \mathrm{O}_{2}$ application at a suitable dose could enhance the removal of the septic/swampy odor while suppressing the formation of bromate during ozonation of Huangpu River source water.
\end{abstract}

\section{Introduction}

Ozonation integrated with biological activated carbon $\left(\mathrm{O}_{3}\right.$-BAC) has been widely used for drinking water treatment because of its effectiveness in removing disinfection byproduct precursors (Chu et al., 2012; Ratasuk et al., 2008), odorants such as 2-methylisoborneol (2-MIB), geosmin and $\beta$-ionone (Peter and von Gunten, 2007), and many other odor causing compounds. The discovery of the formation of potentially carcinogenic bromate $\left(\mathrm{BrO}_{3}^{-}\right)$ during ozonation of bromide-containing source water (von Gunten and Hoigné, 1994), however, has greatly compromised the merits of ozone. Many efforts have thus been devoted to the control of bromate formation during ozonation (von Gunten and Oliveras, 1998).

Addition of ammonia or hydrogen peroxide $\left(\mathrm{H}_{2} \mathrm{O}_{2}\right)$

${ }^{*}$ Corresponding author. E-mail: jwyu@ @rcees.ac.cn has been proposed as a practical approach in controlling the formation of bromate (von Gunten and Hoigné, 1994; Mizuno et al., 2011). Ammonia could react with $\mathrm{HOBr} / \mathrm{OBr}^{-}$, an important ozonation intermediate for bromate production (von Gunten and Oliveras, 1998), to form bromamines $\left(\mathrm{NH}_{2} \mathrm{Br}, \mathrm{NHBr}_{2}\right.$ and $\left.\mathrm{NBr}_{3}\right)$ (Hofmann and Andrews, 2001). Although quite effective in suppressing bromate formation, this approach may compromise the oxidation power of ozone due to the consumption of ozone by bromamines, resulting in the release of $\mathrm{Br}^{-}$and $\mathrm{NO}_{3}^{-}$(Hoigné and Bader, 1978; Haag et al., 1984). On the other hand, $\mathrm{H}_{2} \mathrm{O}_{2}$ addition at certain $\mathrm{H}_{2} \mathrm{O}_{2} / \mathrm{O}_{3}$ ratios has been proved to be effective in reducing bromate formation by decomposing molecular ozone and consuming $\mathrm{HOBr} / \mathrm{OBr}^{-}$(Mizuno et al., 2011; Croue et al., 1996). The combination of $\mathrm{O}_{3}$ and $\mathrm{H}_{2} \mathrm{O}_{2}$, at the same time, has been known as an advanced oxidation process, which was widely used for micropollutant removal (von Gunten and 
Oliveras, 1998). Therefore, compared with the ammonia addition approach, the addition of $\mathrm{H}_{2} \mathrm{O}_{2}$ may have the potential merit of enhancing the oxidation of pollutants in source water through the generation of hydroxyl radicals.

Odor control has long been an important issue for drinking water treatment. Ozonation has been proved to be effective for some odor problems (Peter and von Gunten, 2007). In a previous study, however, ozonation could only reduce the earthy-musty odor intensity from 10 to 6 according to the flavor profile analysis method (Bruchet et al., 2004). $\mathrm{H}_{2} \mathrm{O}_{2}$ addition was found to be able to enhance the reduction of odor intensity by ozonation (Glaze et al., 1990; Bruchet et al., 2004). Thus there is the possibility to control the formation of bromate and enhance the removal of odorants at the same time by adding $\mathrm{H}_{2} \mathrm{O}_{2}$ in an ozonation process.

The Huangpu River, which is known for its septic/swampy odor associated with seasonal earthy/musty odor (Yu et al., 2009), is an important drinking water source for Shanghai. The removal of odor has long been an important issue for the treatment of Huangpu River source water. However, with a high bromide concentration

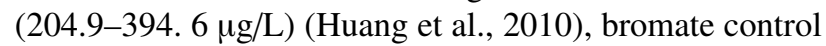
must be considered if ozone is adopted for odor removal. In this study, the possibility of simultaneous control of bromate and odor by adding $\mathrm{H}_{2} \mathrm{O}_{2}$ prior to the $\mathrm{O}_{3}$-BAC process was evaluated in a pilot study, and a suitable $\mathrm{H}_{2} \mathrm{O}_{2} / \mathrm{O}_{3}(\mathrm{~g} / \mathrm{g})$ ratio was proposed. The results of this study will be helpful for better application of ozone for drinking water treatment.

\section{Materials and methods}

\subsection{Setup for the pilot study}

Figure 1 shows the schematic diagram of the $\mathrm{O}_{3}$-BAC system $(120 \mathrm{~L} / \mathrm{hr})$ used for this study. Huangpu River water was treated in a conventional treatment process including coagulation, sedimentation and sand filtration, and then fed into the $\mathrm{O}_{3}$-BAC system. Ozone gas was supplied into the

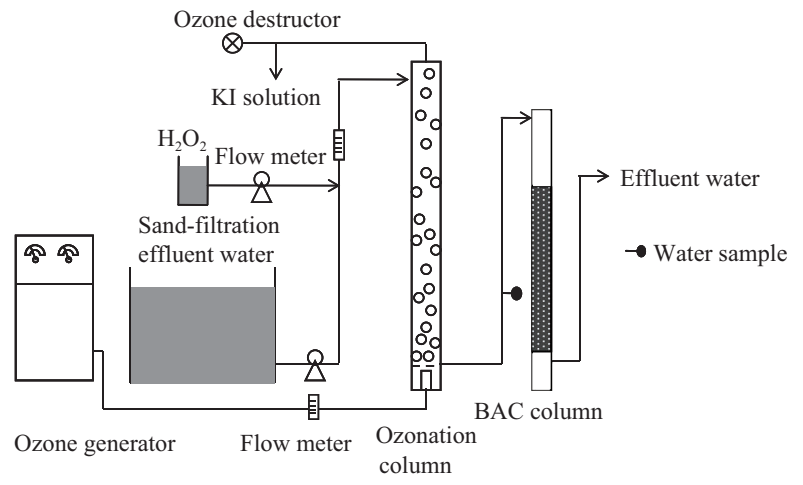

Fig. 1 Schematic diagram of the $\mathrm{O}_{3}-\mathrm{BAC}$ system. ozonation column (height, $1500 \mathrm{~mm}$; inner diameter, 130 $\mathrm{mm}$; effective volume, $18.1 \mathrm{~L}$ ) from the gas diffuser located at the bottom. The hydraulic retention time (HRT) was 9.1 min for ozonation. $\mathrm{H}_{2} \mathrm{O}_{2}$ was added into water before ozonation using a pump. Ozonated water flowed into the BAC column (carbon height, $1000 \mathrm{~mm}$; inner diameter, $130 \mathrm{~mm}$ ) in a down-flow mode with an empty bed contact time of $12.0 \mathrm{~min}$. BAC of approximately 2.5 years age was taken from the BAC tank of a full scale waterworks using surface water as raw water.

The experiment was performed from September to November in 2010 after a two-month pre-operation. The characteristics of raw water and sand filtered water are shown in Table 1. All the samples were stored at $4^{\circ} \mathrm{C}$ and analyzed in one week.

\subsection{Analytical methods}

All reagents applied in the experiment were of analytical grade, and all stock solutions were prepared with Milli-Q water (Millipore).

The indigo method was employed to measure the aqueous ozone concentrations (Bader and Hoigné, 1981), and gaseous phase ozone was quantified by the iodometric method (APHA, 1995). Ozone consumption was defined as the difference between the influent and effluent gaseous ozone. Hydrogen peroxide was determined by the peroxidase-DPD method (Bader et al., 1988). The DOC was determined using a Shimadzu TOC analyzer (TOC-Vcph). Bromate and bromide concentrations were analyzed by ion chromatography (Dionex 3000) using an AC9-SC analytical column with a detection limit of 2.0 $\mu \mathrm{g} / \mathrm{L}$ and $10.0 \mu \mathrm{g} / \mathrm{L}$, respectively.

The taste \& odor intensity of water samples was determined using the flavor profile analysis method, which was described in standard methods (APHA, 1995). In this test, four panelists were trained for the panel. They assigned an intensity rating to each water sample using a

\begin{tabular}{lll}
$\begin{array}{l}\text { Table } 1 \text { Characteristics of Huangpu River raw water and sand filtered } \\
\text { water }\end{array}$ & Raw water & Sand filtered water \\
Parameter & $13-18$ & $14.2-18.5$ \\
\hline Temperature $\left({ }^{\circ} \mathrm{C}\right)$ & $16.4-39.6$ & $0.26-0.96$ \\
Turbidity $(\mathrm{NTU})$ & $0.51-0.84$ & $0.17-0.23$ \\
Ammonia $(\mathrm{mg} / \mathrm{L})$ & $4.98-5.21$ & $3.44-3.71$ \\
DOC $(\mathrm{mg} / \mathrm{L})$ & $207.7-286.2$ & $103.7-236.1$ \\
THMFP $(\mu \mathrm{g} / \mathrm{L})$ & $256.2-291.9$ & $178.31-202.0$ \\
HAAFP $(\mu \mathrm{g} / \mathrm{L})$ & $6.13-17.08$ & $6.86-20.66$ \\
2-MIB $(\mathrm{ng} / \mathrm{L})$ & $2.68-3.79$ & $1.95-4.06$ \\
Geosmin $(\mathrm{ng} / \mathrm{L})$ & $215.2-417.3$ & $215.2-380.5$ \\
Bromide $(\mu \mathrm{g} / \mathrm{L})$ & $8.0-10.0$ & $6.0-9.0$ \\
Septic/swampy odor intensity &
\end{tabular}

* Septic/swampy odor intensity was analyzed by the flavor profile analysis method. THMFP: trihalomethane formation potential; HAAFP: haloacetic acid formation potential. 
7-point category scale: $0=$ not detectable odor, $2=$ very weak, 4 = weak, 6 = weak-to-moderate, $8=$ moderate, $10=$ moderate-to-strong, $12=$ strong. The descriptor and intensity for each sample was then evaluated and recorded. 2-MIB and geosmin concentrations of water samples were analyzed based on the processes of a previous study (Yu et al., 2009).

\section{Results and discussion}

\subsection{Odor removal and bromate formation during $\mathrm{O}_{3}$ - BAC treatment}

Offensive odor of the septic/swampy type was found to be the characteristic odor in Huangpu River water (Yu et al., 2009), with an intensity of 8.0-10.0 during the study, which was decreased slightly to 6.0-9.0 after conventional treatment (Table 1). As shown in Fig. 2, the septic/swampy odor was removed from an intensity of 6.8 to 2.6 with an ozone dose of $3.8-4.9 \mathrm{mg} / \mathrm{L}$, showing that this odor was very difficult to remove. The subsequent BAC treatment could remove the odor effectively from an intensity of 6.8 to 2.4 even without ozonation. It is not clear that what were the major compounds responsible for the septic/swampy odor, although some sulfur-containing compounds such as dimethyl trisulfide were suspected to contribute to this odor (Yu et al., 2009). It has been found that dimethyl trisulfide could be removed effectively by a biologically active sand filter (Lundgren et al., 1988). At the same time, adsorption may also be important for the odor removal (Hrudey et al., 1995). However, even with the combination of $\mathrm{O}_{3}$ and BAC, complete odor removal was only achieved at an ozone dose of $4 \mathrm{mg} / \mathrm{L}$.

2-MIB was detected with a concentration of 6.86-20.66 $\mathrm{ng} / \mathrm{L}$ in sand-filtered water. As shown in Fig. S1, the 2-MIB

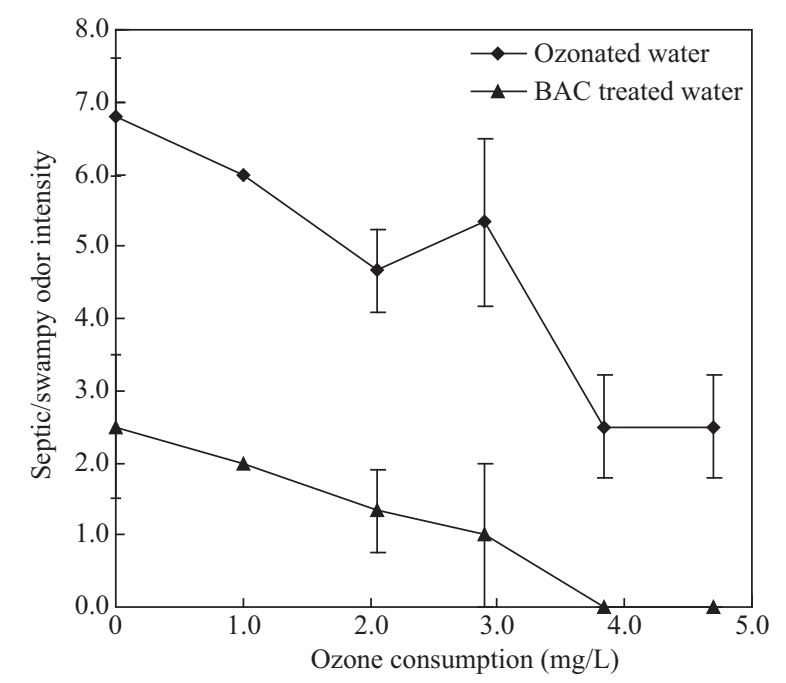

Fig. 2 Change of septic/swampy odor intensity as a function of ozone dose. concentration in both ozonated and BAC-treated water decreased with the increase of ozone dose, and was below detection limit in the BAC-treated water at an ozone dose of $2.0 \mathrm{mg} / \mathrm{L}$.

Figure 3 shows the formation of bromate as a function of ozone dose. With bromide concentration of 215.2-380.5 $\mu \mathrm{g} / \mathrm{L}$ in the sand-filtered water, the bromate concentration increased quickly with increasing ozone dose. The bromate concentration corresponding to a frequently applied ozone dose of $3.0 \mathrm{mg} / \mathrm{L}$ was $17.2 \mu \mathrm{g} / \mathrm{L}$, much higher than the standard level of $10 \mu \mathrm{g} / \mathrm{L}$. Even at an ozone dose of 2.0 $\mathrm{mg} / \mathrm{L}$, the bromate concentration $(11.4 \mu \mathrm{g} / \mathrm{L})$ could exceed the standard level, and it could not be removed during the BAC treatment processes. However, an ozone dose of 2.0 or $3.0 \mathrm{mg} / \mathrm{L}$ could not remove the septic/swampy odor effectively by ozonation alone, as exhibited in Fig. 2. Weak septic/swampy odor could be detected even after the BAC treatment. Thus further efforts are required to remove the septic/swampy odor while controlling the bromate formation simultaneously.

\subsection{Effects of $\mathrm{H}_{2} \mathrm{O}_{2}$ addition on odor removal and bromate control}

Figure 4 displays the bromate concentration as a function of $\mathrm{H}_{2} \mathrm{O}_{2} / \mathrm{O}_{3}$ ratio at two ozone doses $(2.0$ and $3.0 \mathrm{mg} / \mathrm{L})$. With an $\mathrm{H}_{2} \mathrm{O}_{2} / \mathrm{O}_{3}(\mathrm{~g} / \mathrm{g})$ ratio of 0.5 , the bromate concentration decreased significantly from $11.5 \mu \mathrm{g} / \mathrm{L}$ and $17.2 \mu \mathrm{g} / \mathrm{L}$ to $1.9 \mu \mathrm{g} / \mathrm{L}$ and $1.8 \mu \mathrm{g} / \mathrm{L}$, respectively, at the two ozone doses, indicating that $\mathrm{H}_{2} \mathrm{O}_{2}$ addition was very effective in suppressing bromate formation (Daniel et al., 1995). This $\mathrm{H}_{2} \mathrm{O}_{2} / \mathrm{O}_{3}$ ratio was lower than that suggested by Mizuno et al. (2011), which may result from the relatively high residual $\mathrm{H}_{2} \mathrm{O}_{2}$ in the reaction system. After ozonation, more than $30 \%$ of $\mathrm{H}_{2} \mathrm{O}_{2}$ remained in the treated water (inset Fig. 4) and $\mathrm{H}_{2} \mathrm{O}_{2}$ could react with $\mathrm{HOBr}^{-} / \mathrm{OBr}^{-}$, which is an important intermediate in forming bromate, with

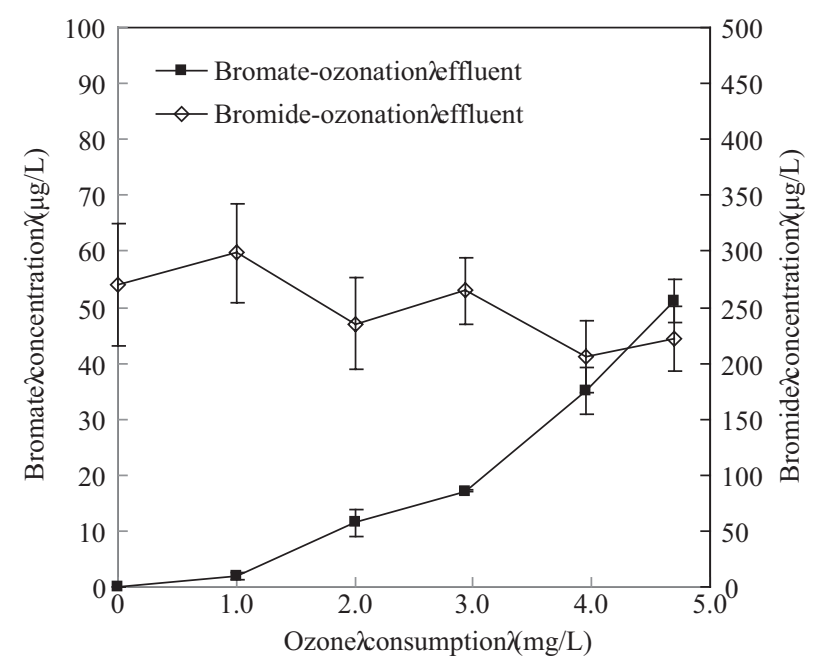

Fig. 3 Bromate formation as a function of ozone dose. 


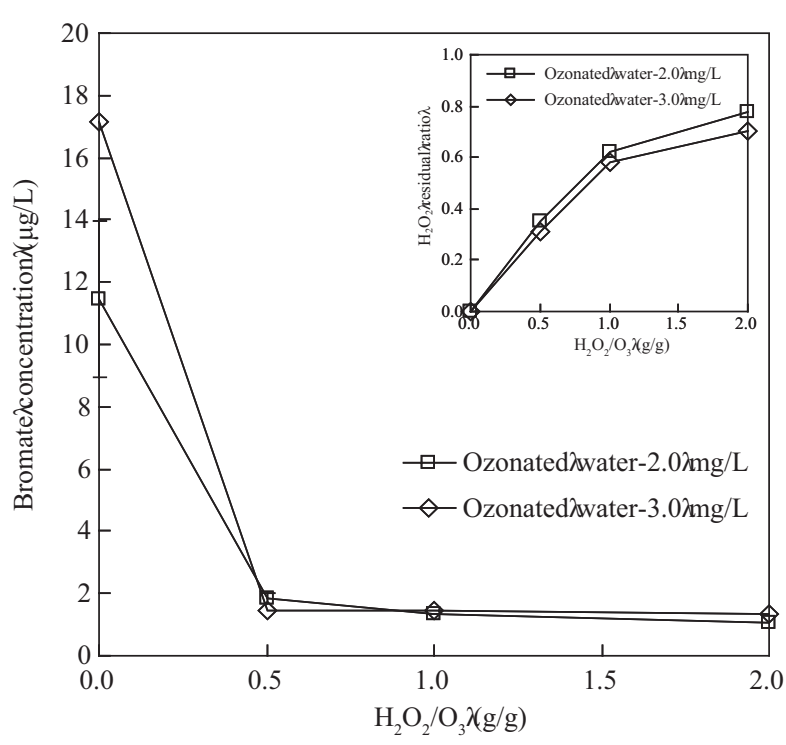

Fig. 4 Effect of $\mathrm{H}_{2} \mathrm{O}_{2}$ addition on bromate control. The inset is the $\mathrm{H}_{2} \mathrm{O}_{2}$ residual ratio $\mathrm{H}_{2} \mathrm{O}_{2}$ concentration/initial $\mathrm{H}_{2} \mathrm{O}_{2}$ concentration at different $\mathrm{H}_{2} \mathrm{O}_{2} / \mathrm{O}_{3}(\mathrm{~g} / \mathrm{g})$ ratios.

reaction rate constant of $7.6 \times 10^{8} \mathrm{~mol} /(\mathrm{L} \cdot \mathrm{sec}$ ) (von Gunten and Oliveras, 1997), inducing the lower concentration of bromate. The optimal $\mathrm{H}_{2} \mathrm{O}_{2} / \mathrm{O}_{3}$ ratio for bromate control may be different for different source water because many factors such as bromide, ammonia, background natural organic materials, and temperature could affect the ozone decomposition and hydroxyl radical concentration in water (von Gunten and Oliveras, 1998; von Gunten and Hoigné, 1994).

Figure 5 displays the decrease of the septic/swampy odor intensity as a function of $\mathrm{H}_{2} \mathrm{O}_{2} / \mathrm{O}_{3}$ ratio. It was clearly demonstrated that the addition of $\mathrm{H}_{2} \mathrm{O}_{2}$ could enhance the removal of the septic/swampy odor. However, there existed an optimum $\mathrm{H}_{2} \mathrm{O}_{2} / \mathrm{O}_{3}$ ratio for each ozone dose. At an

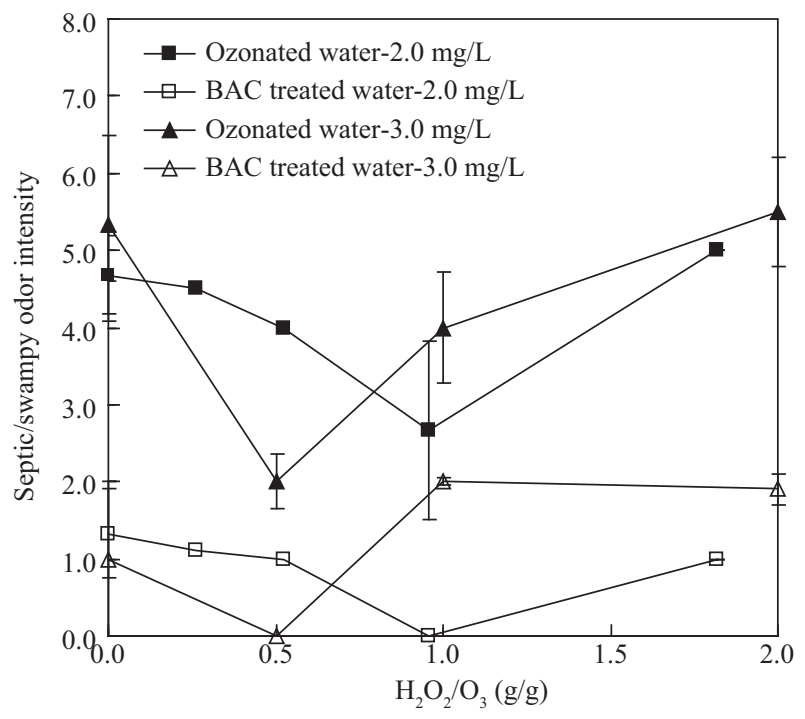

Fig. 5 Effect of $\mathrm{H}_{2} \mathrm{O}_{2}$ addition on septic/swampy odor removal. ozone dose of 2.0 and $3.0 \mathrm{mg} / \mathrm{L}$, the best odor removal efficacy was obtained at an $\mathrm{H}_{2} \mathrm{O}_{2} / \mathrm{O}_{3}$ ratio of 0.5 and 1.0, respectively. The enhancement in odor removal decreased at higher $\mathrm{H}_{2} \mathrm{O}_{2} / \mathrm{O}_{3}$ ratio, which might be the consequence of reactions between excessive amounts of $\mathrm{H}_{2} \mathrm{O}_{2}$ (inset Fig. 4) and $\mathrm{OH}$ radicals (von Gunton and Oliveras, 1998; Kleiser and Frimmel, 2000).

Figure S2 displays the 2-MIB residual ratio (2-MIB/2$\mathrm{MIB}_{0}$ ) in the $\mathrm{H}_{2} \mathrm{O}_{2}-\mathrm{O}_{3}$ treated water at the ozone doses of 2.0 and $3.0 \mathrm{mg} / \mathrm{L}$. The residual ratio decreased as the $\mathrm{H}_{2} \mathrm{O}_{2}$ doses increased from 0 to 1.0 , indicating that the removal of 2-MIB by ozonation was enhanced as $\mathrm{H}_{2} \mathrm{O}_{2}$ was applied. However, MIB could not be detected in the BAC treated water at the different $\mathrm{H}_{2} \mathrm{O}_{2}$ doses.

As discussed above, the addition of $\mathrm{H}_{2} \mathrm{O}_{2}$ could not only suppress the formation of bromate, but also enhance the removal of the septic/swampy odor. However, a suitable $\mathrm{H}_{2} \mathrm{O}_{2}$ dose should be determined to achieve the best performance.

\section{Conclusions}

This study investigated the possibility of simultaneous control of bromate and odor by adding $\mathrm{H}_{2} \mathrm{O}_{2}$ into an ozonation process for the treatment of Huangpu River water. The following conclusions were obtained: (1) Septic/swampy odor as the major odor problem for Huangpu River water could be completely removed by the combination of $\mathrm{O}_{3}$ and BAC at an ozone dose as high as $4 \mathrm{mg} / \mathrm{L}$, which would produce high concentrations of bromate. (2) By adding $\mathrm{H}_{2} \mathrm{O}_{2}$ with an $\mathrm{H}_{2} \mathrm{O}_{2} / \mathrm{O}_{3}$ ratio of 0.5 , it was possible to remove the septic/swampy odor and suppress the formation of bromate by the combination of $\mathrm{O}_{3}$ and $\mathrm{BAC}$ at an ozone dose of $2.0 \mathrm{mg} / \mathrm{L}$. The suitable $\mathrm{H}_{2} \mathrm{O}_{2}$ dose should be determined according to raw water quality and the ozone dose.

\section{Acknowledgment}

This work was supported by the National Natural Science Foundation of China (No. 50938007), the Funds for Major Science and Technology Program for Water Pollution Control and Treatment (No. 2012ZX07403-002-02), and the Shanghai Committee of Science and Technology Project (No. 11XD1420500).

\section{Supporting materials}

Supplementary data associated with this article can be found in the online version.

R E F E R E N C E S

APHA, AWWA, WEF, 1995. Standard methods for the examination of water and wastewater. American Public Health Association, 19th 
ed. Washington, DC.

Bader, H., Hoigné, J., 1981. Determination of ozone in water by the indigo method. Water Res. 15(4), 449-456.

Bader, H., Sturzenegger, V., Hoigné, J., 1988. Photometric method for the determination of low concentrations of hydrogen peroxide by the peroxidase catalyzed oxidation of $N, N$-diethyl- $p$ phenylenediamine (DPD). Water Res. 22(9), 1109-1115.

Bruchet, A., Duguet, J. P., Suffe, I. H., 2004. Role of oxidants and disinfectants on the removal, masking and generation of tastes and odours. Rev. Environ. Sci. Biotechnol. 3(1), 33-41.

Chu, W., Gao, N., Yin, D., Deng, Y., Templeton, M. R., 2012. Ozonebiological activated carbon integrated treatment for removal of precursors of halogenated nitrogenous disinfection by-products. Chemosphere 86(11), 1087-1091.

Croue, J. P., Koudjonou, B. K., Legube, B., 1996. Parameters affecting the formation of bromate ion during ozonation. Ozone: Sci. Eng. $18(1), 1-18$.

Daniel, P. A., Zafer, M. A., Meyerhofer, P. F., 1995. Bromate control: Water quality, engineering, and operational considerations. Water Suppl.13(1), 169-176.

Glaze, W. H., Schep, R., Chauncey, W., Ruth, E. C., Zarnoch, J. J., Aieta, E. M. et al., 1990. Evaluating oxidants for the removal of model taste and odor compounds from a municipal water supply. J. Amer. Water Works Assoc. 82(5), 79-84.

Haag, W. R., Hoigné, J., Bader, H., 1984. Improved ammonia oxidation by ozone in the presence of bromide ion during water treatment. Water Res. 18(9), 1125-1128.

Hofmann, R., Andrews, R. C., 2001. Ammoniacal bromamines: A review of their influence on bromate formation during ozonation. Water Res. 35(3), 599-604.

Hoigné, J., Bader, H., 1978. Ozonation of water: kinetics of oxidation of ammonia by ozone and hydroxyl radicals. Environ. Sci. Technol.12(1), 79-84.

Hrudey, S. E., Huck, P. M., Mitton, M. J., Kenefick, S. L., 1995.
Evaluation of odour removal by pilot-scale biological treatment process trains during spring runoff in an ice-covered river. Water Sci. Technol. 31(11), 195-201.

Huang, X., Mei, H., Ding, G., Lu, N., 2010. Bromate formation during ozonation in bromide-containing Huangpu River water. J. Shanghai Univ. (Nat. Sci. Ed. ) 16(5), 498-502.

Kleiser, G., Frimmel, F. H., 2000. Removal of precursors for disinfection by-products (DBPs)-differences between ozone-and OH-radicalinduced oxidation. Sci. Total Environ. 256(1), 1-9.

Lundgren, B. V., Grimvall, A., Sävenhed, R., 1988. Formation and removal of off-flavour compounds during ozonation and filtration through biologically active sand filters. Water Sci. Technol. 20(89), 245-253.

Mizuno, T., Ohara, S., Nishimura, F., Tsuno, H., 2011. $\mathrm{O}_{3} / \mathrm{H}_{2} \mathrm{O}_{2}$ process for both removal of odorous algal-derived compounds and control of bromate ion formation. Ozone: Sci. Eng. 33(2), 121-135.

Peter, A., von Gunten, U., 2007. Oxidation kinetics of selected taste and odor compounds during ozonation of drinking water. Environ. Sci. Technol. 41(2), 626-631.

Ratasuk, C., Kositanont, C., Ratanatamskul, C., 2008. Removal of haloacetic acids by ozone and biologically active carbon. J. Sci. Soc. Thai 34, 293-298.

von Gunten, U., Hoigné, J., 1994. Bromate formation during ozonization of bromide-containing waters: interaction of ozone and hydroxyl radical reactions. Environ. Sci. Technol. 28(7), 1234-1242.

von Gunten, U., Oliveras, Y., 1997. Kinetics of the reaction between hydrogen peroxide and hypobromous acid: Implication on water treatment and natural systems. Water Res. 31(4), 900-906.

von Gunten, U., Oliveras, Y., 1998. Advanced oxidation of bromidecontaining waters: Bromate formation mechanisms. Environ. Sci. Technol. 32(1), 63-70.

Yu, J., Zhao, Y., Yang, M., Tsair-Fuh, L., Guo, Z., Gu, J. et al., 2009. Occurrence of odour-causing compounds in different source waters of China. J. Water Supp. 58(8), 587-594. 